\title{
Prevalence of Prodromal Symptoms of Parkinson's Disease in the Late Middle-Aged Population
}

\author{
Dareia S. Roos ${ }^{\mathrm{a}, *, 1}$, Martin Klein ${ }^{\mathrm{b}, 2}$, Dorly J.H. Deeg ${ }^{\mathrm{c}, \mathrm{d}}$, Richard L. Doty ${ }^{\mathrm{e}}$ and Henk W. Berendse ${ }^{\mathrm{a}}$ \\ ${ }^{a}$ Department of Neurology, Amsterdam Neuroscience, Amsterdam UMC, Vrije Universiteit Amsterdam, \\ Amsterdam, The Netherlands \\ ${ }^{\mathrm{b}}$ Department of Medical Psychology, Amsterdam UMC, Vrije Universiteit Amsterdam, Amsterdam, \\ The Netherlands \\ ${ }^{\mathrm{c}}$ Department of Epidemiology and Data Science, Amsterdam UMC, Vrije Universiteit Amsterdam, Amsterdam \\ d Public Health Research Institute, Amsterdam UMC, Amsterdam, The Netherlands \\ ${ }^{\mathrm{e}}$ Smell and Taste Center, Perelman School of Medicine, University of Pennsylvania, Philadelphia, PA, USA
}

Accepted 31 January 2022

Pre-press 16 February 2022

\begin{abstract}
.
Background: The prodromal phase of Parkinson's disease (PD) can last up to 20 years and is characterized by a variety of non-motor symptoms.

Objective: To determine the prevalence of a selection of non-motor symptoms known to be associated with an increased risk of developing PD in a late middle-aged population-based sample and to determine their association with motor function.

Methods: At a mean age of 60.3 years, 775 subjects were recruited from the Longitudinal Aging Study Amsterdam (LASA). Hyposmia, cognitive impairment, patient-reported constipation, possible REM-sleep behavior disorder, depression, and anxiety were indexed as known PD risk factors. Additionally, 1) the PD screening questionnaire, 2) four physical performance tests, and 3) a functional limitations questionnaire, were used to determine whether the presence of two or more PD risk factors was associated with reduced motor function.

Results: The prevalence of single risk factors ranged between 3 and 13\%. Approximately $11 \%$ of subjects had two or more PD risk factors. Motor functioning of subjects with two or more PD risk factors was significantly worse than performance of subjects without or with a single risk factor (all $p$ values $\leq 0.001$ ).

Conclusion: Approximately $11 \%$ of the late middle-aged population has two or more known PD risk factors. Among these subjects self-perceived PD symptoms and reduced physical performance are more prevalent, suggesting that at least some of these subjects may be in the prodromal phase of PD.
\end{abstract}

Keywords: Parkinson's disease, prodromal symptoms, hyposmia, risk factors

\footnotetext{
*Correspondence to: Dareia S. Roos, MD, Department of Neurology, Amsterdam Neuroscience, Amsterdam UMC, Vrije Universiteit Amsterdam, De Boelelaan 1117, Amsterdam, The Netherlands. Tel.: +0031 020 4442834; E-mail: d.roos@amster damumc.nl.

${ }^{1}$ ORCID: 0000-0001-7961-1768.

${ }^{2}$ ORCID: 0000-0003-4160-5746.
}

\section{INTRODUCTION}

Parkinson's disease (PD) is one of the most common neurodegenerative disorders, affecting millions of individuals worldwide [1]. The prodromal phase of the disease is characterized by a range of non-motor symptoms that can predate the onset of the classical 
motor symptoms for many years. These symptoms include constipation, hyposmia, possible REM-sleep behavior disorder (RBD), depression, anxiety disorder, and cognitive impairment [2]. Constipation is among the first prodromal signs, occurring up to 20 years prior to the first motor symptoms [3]. RBD, olfactory dysfunction and depression may also precede a diagnosis of (motor) PD by as long as 10 years [4-6].

Lewy bodies and Lewy neurites are considered as the neuropathological hallmarks of the disease. They spread throughout the brain following a predetermined pattern. The earliest pathological changes occur in the nuclei of the glossopharyngeal, vagal and olfactory nerves [7] and are assumed to be causative for various non-motor symptoms.

The presence of a prodromal phase with a still limited involvement of brain areas theoretically provides the opportunity for early neuroprotective treatment aimed at preventing further spreading of disease-specific pathology and subsequent neuronal death. Various ongoing studies are currently examining disease-modifying treatments [8]. However, the symptoms associated with prodromal PD are not specific to PD and can also be caused by other diseases. It is therefore unlikely that prodromal PD can be diagnosed based on one single prodromal marker. Instead, the coincidence of multiple markers (risk factors) in a single individual may be a more reliable indicator of prodromal PD.

Earlier population-based studies examined various prodromal symptoms in relation to PD. The Honolulu-Asia Aging Study (HAAS) examined olfaction, constipation, executive functioning, and excessive daytime sleepiness in elderly subjects (mean age 79.7 years) [9], and revealed that persons with two or more risk factors had a 10-fold increase in the risk of developing PD. The Prospective evaluation of Risk factors for Idiopathic Parkinson's Syndrome (PRISP) study, including participants with a mean age of 59 years, found that the combination of prescreening for age, a positive family history and/or hyposmia and secondary screening for enlarged substantia nigra hyperechogenicitiy predicted PD [10]. In the Parkinson At-Risk Syndrome (PARS) study the number of other non-motor symptoms (anxiety, RBD and constipation) was higher in hyposmic subjects than in normosmic subjects, who were approximately 64 years old [11].

In this study we examined the widest range of nonmotor PD risk factors to date in a single population. In the Longitudinal Aging Study Amsterdam (LASA)
[12], a large population-based study of late middle aged subjects, we assessed the prevalence of constipation, hyposmia, possible RBD, depression, anxiety and cognitive impairment. In addition, we analyzed the association between the presence of two or more of these risk factors in a single individual with three indices of motor function.

\section{METHODS}

\section{Subjects}

Data were collected as part of the ongoing, prospective Dutch Longitudinal Aging Study Amsterdam (LASA) cohort [12]. The main goal of LASA is to determine predictors and consequences of changes in functioning with aging. The study aims are described elsewhere in more detail [12]. The third cohort of subjects aged 55-64 was recruited from population registries and included 1,023 subjects who were interviewed and tested in their homes in 2012 and 2013. The data collection consisted of three elements: 1) the main interview, 2) self-administered questionnaires, and 3) a medical interview (http://www.lasa-vu.nl) [12]. The data was collected by trained interviewers and the interviews were audio-recorded for quality checks. Data on chronic diseases were self-reported and medication use in the last two weeks was collected. The LASA study protocol was conducted in line with the Declaration of Helsinki and approved by the medical ethics committee of the VU University Medical Center. For the study, subjects with a known formal diagnosis of PD or subjects who used dopamine replacement therapy at a dosage normally used in PD $(n=2)$ were excluded. In addition, we excluded individuals of whom not all information on each risk factor was available. The final study sample included 775 subjects.

\section{Risk factors}

We analyzed the prevalence of six non-motor prodromal symptoms of PD systematically documented in the LASA study, namely: hyposmia, cognitive impairment, possible RBD, constipation, depression, and anxiety. Previous research established that these prodromal symptoms are PD risk factors.

Olfactory function was assessed using the Dutch version of the University of Pennsylvania Smell Identification Test (UPSIT) [13]. The UPSIT is a self-administered forced-choice odor identification 
test, consisting of 40 different micro-encapsulated odors. Subjects are instructed to scratch a patch with micro pellets, smell the odor that is released, and choose the best alternative from four response alternatives. The total score was calculated by adding up the correct answers. The average of non-missing values was used to impute up to two missing values. Since there are no validated cut-off scores available for the Dutch population, an abnormal score was defined as a score lower than two standard deviations from the mean UPSIT score of the total group (mean score 31.88 points, SD 4.73). Global cognitive functioning was assessed using the Mini-Mental State Examination (MMSE) [14]. A score of 24 (out of 30) points or lower was defined as indicative of cognitive impairment [15].

The other prodromal symptoms, i.e., constipation, possible RBD and signs of depression and anxiety, were assessed using questionnaires administered to each subject. The single-question screen for RBD [16] was used to screen for the presence of possible RBD. Frequency of bowel movements was used to establish the presence of constipation. Passing stool less than once a day was labeled as a risk factor based upon the results of previous research [3].

The Center for Epidemiologic Studies Depression Scale (CES-D) [17] and the Hospital Anxiety and Depression Scale - subscale Anxiety (HADS-A) [18] were used to screen for depression and anxiety, respectively. The CES-D consists of 20 items, with a total score between 0 and 60 [17]. A score of 16 points or higher marks a clinically relevant depression [19], and was used in this cohort as a PD risk factor. The HADS-A consists of 7 items, with a total score between 0 and 21. A higher score corresponds with more anxiety. Presence of anxiety was defined as a score of 8 points and higher [20].

\section{Motor function}

Motor function was assessed using three indices ranging from the presence of subjective motor symptoms to the level of the activities of daily living.

Firstly, a Dutch translation of a screening questionnaire designed by Tanner [21] and validated by Duarte [22], was used to screen for motor symptoms potentially indicative of parkinsonism. The questionnaire consists of nine questions focusing on the characteristic motor symptoms of PD. As defined in earlier studies, a score of three or more points was considered indicative of the presence of parkinsonism.
Secondly, physical performance was assessed using four tasks. The first task involved walking as quickly as possible for 3 meters, turning around and walking back 3 meters. The total time needed to perform this test was recorded in seconds and categorized as: 0) unable to perform task, and quartiles: 1) $\geq 10 \mathrm{~s}, 2) 8-9 \mathrm{~s}, 3) 6-7 \mathrm{~s}$, and 4) $<6 \mathrm{~s}$. In the second task, subjects were asked to stand up from a chair with folded arms and sit down again for five times. The total time to perform these five repetitions was recorded in seconds and categorized as: 0 ) unable to perform task, and the quartiles: 1) $\geq 15$ s 2) $12-14$ s, 3) $10-11 \mathrm{~s}$, and 4$) \leq 9 \mathrm{~s}$. In the third task, subjects were asked to put on and take off a cardigan. The time to perform this task was recorded in seconds and categorized as: 0) unable to perform, and the quartiles: 1) $\geq 16 \mathrm{~s}$, 2) $12-15 \mathrm{~s}, 3) 9-11 \mathrm{~s}$, and 4) $\leq 8 \mathrm{~s}$. Lastly, subjects were asked to stand in tandem position for $30 \mathrm{~s}$. The time to perform this task was also recorded in seconds and categorized as: 0 ) unable to perform, 2) performed it for 3-9 s, or 4) 10 s or longer. The sum score of the four tests was calculated and ranged between 0 and 16 points, a higher score corresponding to better overall physical performance. In addition to the four quantitative measures of physical performance, walking patterns were observed by the interviewers, and classified as normal or abnormal based upon the occurrence of for example starting problems, walking with short steps or an irregular, unstable turn.

Thirdly, functional limitations in the activities of daily living were assessed using a 7-item questionnaire. The rationale behind this questionnaire is described elsewhere [23]. Items assessed were climbing stairs, (un)dressing, getting up and sitting down in a chair, cutting one's own toenails, walking 5 minutes outdoors without resting, using own or public transportation, and taking a bath or shower. Scores on these seven items were summed to a total score that ranged from 0 (does not have any difficulties with the activities) to 7 (has difficulties with all activities).

\section{Statistical analysis}

For each of the risk factors associated with PD, the prevalence in our sample was calculated. In addition, we determined the prevalence of combinations of 2, 3 , and 4 risk factors. As in previous research, when subjects had two or more risk factors for PD, they were defined as high risk subjects [9]. The three measures for motor functioning were compared between the group with two or more risk factors for PD on 
Table 1

Characteristics of subjects

\begin{tabular}{lcccc}
\hline & $\begin{array}{c}\text { Total group } \\
(n=775)\end{array}$ & $\begin{array}{c}0 / 1 \text { risk factor } \\
(n=688)\end{array}$ & $\begin{array}{c}\geq 2 \text { risk factors } \\
(n=87)\end{array}$ & Sign. $(p)$ \\
\hline Age in years - Mean (SD) & $60.3(2.9)$ & $60.4(2.9)$ & $60.2(3.0)$ & \\
Male \% (n) & $48.6(377)$ & $49.6(341)$ & $41.4(36)$ & \\
Diabetes mellitus \% (n) & & $7.4(51)$ & $10.3(9)$ & 0.391 \\
Stroke \% (n) & & $2.0(14)$ & $4.6(4)$ & 0.247 \\
Osteoarthritis \% (n) & & $39.1(269)$ & $50.6(44)$ & $0.048^{*}$ \\
Rheumatoid arthritis \% (n) & & $8.6(59)$ & $10.3(9)$ & 0.687 \\
Heart disease \% (n) & & $10.0(69)$ & $11.5(10)$ & 0.706 \\
\hline
\end{tabular}

* Statistical significant result.

Table 2

Prevalence of six risk factors for PD

\begin{tabular}{lccc}
\hline Putative risk factor & $\begin{array}{c}\text { All cases } \\
(n=775)\end{array}$ & $\begin{array}{c}0 / 1 \text { risk factor } \\
(n=688)\end{array}$ & $\begin{array}{c}\geq 2 \text { risk factors } \\
(n=87)\end{array}$ \\
\hline Olfactory dysfunction \% (n) & $3.9(30)$ & $2.2(15)$ & $17.2(15)$ \\
REM sleep behavior disorder \% (n) & $13.3(103)$ & $9.7(67)$ & $41.4(36)$ \\
Constipation \% (n) & $9.7(75)$ & $7.3(50)$ & $28.7(25)$ \\
Cognitive impairment (MMSE $\leq 24$ points) \% (n) & $2.8(22)$ & $1.2(8)$ & $16.1(14)$ \\
Depression (CES-D $\geq 16$ points) \% (n) & $12.0(93)$ & $4.5(31)$ & $71.3(62)$ \\
Anxiety (HADS-A $\geq 8$ points) \% (n) & $8.8(68)$ & $1.9(13)$ & $63.2(55)$ \\
\hline
\end{tabular}

REM, rapid eye movement; MMSE, Mini-Mental State Examination; CES-D, Center for Epidemiologic Studies Depression Scale; HADS-A, Hospital Anxiety and Depression Scale - subscale Anxiety.

the one hand and the group with one or zero, using either an independent $t$-test or a Mann-Whitney test, depending on the data distribution. The data were analyzed with SPSS version 26.0 (SPSS Inc., Chicago, IL, USA). In all analyses, the significance level was set at 0.05 .

\section{RESULTS}

\section{Prevalence of PD risk factors}

The final sample of 775 subjects consisted of $48.6 \%$ men, with a mean age of 60.3 years (SD 2.9 years) (Table 1). Osteoarthritis was the most common reported chronic disorder among the subjects (Table 1). The prevalence of the six individual risk factors ranged from $2.8 \%$ for cognitive dysfunction to $13.3 \%$ for possible RBD (Table 2). Most subjects had no $(64.3 \%)$ or only one risk factor $(24.5 \%)$, whereas $11.2 \%$ had two or more risk factors. There were no subjects with 5 or 6 risk factors (Table 3 ). The group with no or only one risk factor had a mean age of 60.4 years (SD 2.9) and consisted of $49.6 \%$ males, compared to mean age of 60.2 years (SD 3.0) and $41.4 \%$ males in the group with two or more risk factors (Table 1).

The combination of depression and anxiety was the most common (49 times; 6.3\%), followed by the
Table 3

The prevalence of the number of risk factors for PD

\begin{tabular}{lccc}
\hline $\begin{array}{l}\text { Number of } \\
\text { risk factors }\end{array}$ & $\begin{array}{c}\text { Total group } \\
(\%(\mathrm{n}))\end{array}$ & $\begin{array}{c}\text { Male } \\
(\%(\mathrm{n}))\end{array}$ & $\begin{array}{c}\text { Female } \\
(\%(\mathrm{n}))\end{array}$ \\
\hline 0 & $64.3(498)$ & $69.2(261)$ & $59.5(237)$ \\
1 & $24.5(190)$ & $21.2(80)$ & $27.6(110)$ \\
2 & $7.4(57)$ & $5.8(22)$ & $8.8(35)$ \\
3 & $3.2(25)$ & $3.4(13)$ & $3.0(12)$ \\
4 & $0.6(5)$ & $0.3(1)$ & $1.0(4)$ \\
\hline
\end{tabular}

combination of possible RBD and depression (20 times; $2.6 \%$ ). The least common combination was hyposmia and anxiety (two times; $0.3 \%$ ).

\section{Motor functioning in individuals with two or more risk factors}

Subjects with two or more risk factors reported significantly more symptoms on the PD screening questionnaire compared to the group with no or only one risk factor $(p<0.001$; Table 4$)$. In addition, subjects with two or more risk factors for PD had a significantly lower physical performance score than the group with zero or one risk factor $(p=0.001$; Table 4). Walking abnormalities were recorded in $6.1 \%$ of the subjects with zero or one risk factor, compared to $17.2 \%$ in the group with two or more risk factors for PD. Lastly, subjects with two or more risk factors reported significantly more functional 
Table 4

Mean score on functional limitations questionnaire, physical performance tests, and PD screening questionnaire stratified by number of risk factors

\begin{tabular}{|c|c|c|c|}
\hline & \multicolumn{3}{|c|}{ Total group $(n=775)$} \\
\hline & $\begin{array}{c}0 / 1 \text { risk factor } \\
\quad(n=688)\end{array}$ & $\begin{array}{c}\geq 2 \text { risk factors } \\
\quad(n=87)\end{array}$ & Sign. $(p)$ \\
\hline Functional limitations questionnaire $(0-7$ points $)(n=775)^{\text {a }}$ & 0.56 points (SD 1.22) & 1.43 points $(\mathrm{SD} 2.20)$ & $<0.001^{*}$ \\
\hline Physical performance tests ( $0-16$ points $)(n=767)^{\mathrm{b}}$ & 12.69 points (SD 2.18 ) & 11.68 points $(\mathrm{SD} 2.71)$ & $0.001^{*}$ \\
\hline PD screening questionnaire $(0-9$ points $)(n=774)^{\text {a }}$ & 0.38 points (SD 0.85$)$ & 0.89 points (SD 1.39) & $<0.001^{*}$ \\
\hline
\end{tabular}

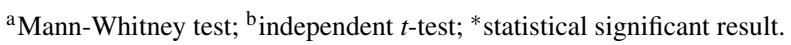

limitations compared to the group with no or only one risk factor (mean 0.56 points versus 1.43 points, $p<0.001$; Table 4). When excluding subjects $(n=34)$ who were unable to perform one or more of the physical performance tasks mostly due to osteoarthritis, the results remained the same (Supplementary Table 1).

\section{DISCUSSION}

In the present cross-sectional study of communitydwelling late middle-aged adults, we observed a prevalence ranging between 3 and $12 \%$ for six known risk factors for developing PD, i.e., hyposmia (UPSIT), possible RBD (single-item questionnaire), patient-reported constipation, depression (CES-D), anxiety (HADS-A), and cognitive impairment (MMSE). More than $11 \%$ of subjects had two or more risk factors for developing PD. Interestingly, these subjects reported significantly more motor symptoms indicative of parkinsonism and functional limitations in daily life, and additionally had poorer physical performance than those with a single or no risk factors.

The UPSIT is one of the best-validated olfactory tests to screen for olfactory dysfunction [13]. However, at present, no validated cut-off scores are available for the Dutch population. Therefore, we defined normosmia as an UPSIT score within 2 standard deviations from the mean. Using this criterion, the prevalence of hyposmia in our population was close to $4 \%$, which is comparable to the prevalence found in previous studies [24].

In this cohort, $13 \%$ of subjects screened positive on the RBD single-item questionnaire [16], suggesting possible RBD. Although this percentage is comparable to two previous studies using the same questionnaire in a general adult population [25, 26], a population-based study also using the single-item questionnaire found a lower prevalence of 3.2\% [27]. In the latter study patients with apnea or non-REM parasomnia were excluded, which may at least partly explain the discrepancy. In a Spanish study, the prevalence of possible RBD was $5.2 \%$ when based upon the single-item questionnaire, whereas using videopolysomnography the prevalence of RBD was only $0.74 \%$ [28]. Although clearly a definite diagnosis of RBD requires video-polysomnography, this procedure is not feasible as a screening tool in the general population.

Almost $10 \%$ of subjects in our cohort had constipation defined as passing stool less than once a day, which is comparable to observations in previous studies [29]. Constipation is associated with an increased risk of developing PD [3]. In a retrospective analysis in a primary care population, patients with $P D$ more often reported constipation in the years prior to diagnosis compared to patients without PD [30]. In the same study, constipation appeared to be the most common autonomic symptom in the two years prior to diagnosis. According to the results of two other studies focusing on constipation as a prodromal symptom of PD, the prodromal phase of PD may be as long as 12 or even 20 years [31, 32].

Almost $3 \%$ of subjects in this cohort had an MMSE score indicative of dementia, in spite of the fact that these subjects did not report a diagnosis of dementia or the presence of cognitive impairment. In the general population the prevalence of mild cognitive impairment is 10-20\% [33] and the prevalence of dementia $0.8 \%$ [34]. In the Rotterdam study cognitive impairment, assessed using a combination of neuropsychological tests, was associated with an increased risk of developing PD over a mean period of 8 years [35]. Similarly, in another communitybased study, the Honolulu-Asia Aging Study, using the cognitive abilities screening instrument (CASI), cognitive decline was found to precede PD [9].

The most extensively studied neuropsychiatric prodromal symptoms of PD are depression and anxiety. In the general population aged over 55 years of age, around $14 \%$ suffers from depression [36]. In line with this observation, $12 \%$ of subjects in the present 
cohort had signs of a clinically relevant depression. In a recent meta-analysis with a mean follow-up period of 10 years, a diagnosis of depression at baseline was associated with an increased the risk of later developing PD (RR 2.2, CI 1.87-2.58) [5].

In our study sample, almost $9 \%$ of subjects had signs of an anxiety disorder, corresponding to the prevalence reported by Fung et al. [37]. Like depression, an anxiety disorder is also associated with the risk of developing PD [30]. Shiba et al reported an odds ratio of 2.2 for developing PD in individuals suffering from an anxiety disorder, of 1.9 for depression and even higher for the combination of both (odds ratio 2.4) [38].

Taking into consideration that the non-motor symptoms associated with prodromal PD are not specific to PD, it is unlikely that prodromal PD can be diagnosed based upon the presence of a single risk factor. Therefore, we were most interested in the coincidence of multiple risk factors in a single individual as a potential indicator of prodromal PD. In our present study more than $11 \%$ of subjects had two or more non-motor risk factors for PD. In a recent Japanese study almost $6 \%$ of subjects aged above 50 had two or more prodromal symptoms associated with PD [39].

In the present study, having two or more risk factors for PD was associated with more subjective motor symptoms, a lower level of physical performance, and more functional limitations in the activities of daily life. Since subtle changes in motor functioning can precede the development of full-blown parkinsonism [30], our results suggest that at least some subjects with two or more PD risk factors are in the prodromal phase of PD and may go on to later develop the classical motor signs of the disease. To confirm this hypothesis, longitudinal follow-up of our study sample is necessary.

The strengths of this study include the large number of subjects representative for the late middle-aged population, and the use of reliable and well-validated tests and screening questionnaires. Furthermore, the interviewers were well trained and all interviews were audio-recorded for quality checks. A weakness may be that a formal neurological examination could not be performed, which might have led to an underestimation of the number of cases of (as yet undiagnosed) PD. This was a consequence of the choice to use home visits, which on the other hand probably increased the participation rate. Furthermore, not all known risk factors were evaluated, and RBD, depression or anxiety disorder could not be formally diagnosed in our cohort, as only screening tools were used. Lastly, not including a full neurological examination as part of the follow-up visits may have led to an underestimate of the prevalence of subtle motor signs. However, large cohort studies have demonstrated a high odds ratio for the association between ADL disability and PD [40]. This supports the use of a functional limitations questionnaire as a motor outcome measure when full neurological exams are not regularly possible, such as in the LASA study. Additional, objective assessment of motor functioning can be derived from brief physical performance tests, such as those used in our study.

\section{Conclusion}

In conclusion, in a large sample of community dwelling late middle-aged adults more than $11 \%$ of individuals have two or more established risk factors for developing PD, including hyposmia, constipation, possible RBD, depression, anxiety disorder, and/or cognitive impairment. The higher score on a screening questionnaire for PD-related motor symptoms, the lower level of physical performance, and the increase in functional limitations in individuals with two or more risk factors for PD suggests that at least some of these subjects may go on to develop PD in the upcoming years. Longitudinal follow-up data are necessary to substantiate this assumption and to determine the best-predictive combination of PD risk factors in the late middle-aged population.

\section{ACKNOWLEDGMENTS}

The Longitudinal Aging Study Amsterdam is supported by a grant from the Netherlands Ministry of Health, Welfare and Sport, Directorate of LongTerm Care. The data collection for this study was financially supported by the Netherlands Organization for Scientific Research (NWO) in the framework of the project "New Cohorts of young old in the 21st century" (file number 480-10-014). In addition, the Dutch Parkinson Foundation financially supported the data collection specifically aimed at the assessment of PD risk factors in this cohort.

\section{CONFLICT OF INTEREST}

DR: received research support from the Dutch Parkinson Foundation.

MK \& DD: declare they have no financial interests. 
RD: is president and major shareholder of Sensonics International, the manufacturer and distributor of smell and taste tests, including the olfactory test used in this article. He is a consultant to Eisai Co., Ltd., Merck Pharmaceuticals, the Michael J. Fox Foundation for Parkinson's Research, and Johnson \& Johnson. He receives royalties from Cambridge University Press, Elsevier, Johns Hopkins University Press, McGraw-Hill, and John Wiley \& Sons, Inc.

HB: received research support from the Dutch Parkinson Foundation, ZonMw, and the Michael J Fox Foundation.

\section{SUPPLEMENTARY MATERIAL}

The supplementary material is available in the electronic version of this article: https://dx.doi.org/ 10.3233/JPD-213007.

\section{REFERENCES}

[1] Dorsey ER, Sherer T, Okun MS, Bloem BR (2018) The emerging evidence of the Parkinson pandemic. J Parkinsons Dis 8, S3-S8.

[2] Postuma RB, Berg D (2019) Prodromal Parkinson's disease: The decade past, the decade to come. Mov Disord 34, 665-675.

[3] Adams-Carr KL, Bestwick JP, Shribman S, Lees A, Schrag A, Noyce AJ (2016) Constipation preceding Parkinson's disease: A systematic review and meta-analysis. J Neurol Neurosurg Psychiatry 87, 710-716.

[4] Ponsen MM, Stoffers D, Booij J, van Eck-Smit BL, Wolters E, Berendse HW (2004) Idiopathic hyposmia as a preclinical sign of Parkinson's disease. Ann Neurol 56, 173-181.

[5] Wang S, Mao S, Xiang D, Fang C (2018) Association between depression and the subsequent risk of Parkinson's disease: A meta-analysis. Prog Neuropsychopharmacol Biol Psychiatry 86, 186-192.

[6] Scott GD, Lim MM, Drake MG, Woltjer R, Quinn JF (2021) Onset of skin, gut, and genitourinary prodromal Parkinson's disease: A study of 1.5 million veterans. Mov Disord 36, 2094-2103.

[7] Braak H, Del Tredici K, Rub U, de Vos RA, Jansen Steur EN, Braak E (2003) Staging of brain pathology related to sporadic Parkinson's disease. Neurobiol Aging 24, 197-211.

[8] McFarthing K, Buff S, Rafaloff G, Dominey T, Wyse RK, Stott SRW (2020) Parkinson's disease drug therapies in the clinical trial pipeline: 2020. J Parkinsons Dis 10, 757-774.

[9] Ross GW, Abbott RD, Petrovitch H, Tanner CM, White LR (2012) Pre-motor features of Parkinson's disease: The Honolulu-Asia Aging Study experience. Parkinsonism Relat Disord 18 (Suppl 1), S199-202.

[10] Berg D, Godau J, Seppi K, Behnke S, Liepelt-Scarfone I, Lerche S, Stockner H, Gaenslen A, Mahlknecht P, Huber H, Srulijes K, Klenk J, Fassbender K, Maetzler W, Poewe W, group Ps (2013) The PRIPS study: Screening battery for subjects at risk for Parkinson's disease. Eur J Neurol 20, 102-108.
[11] Siderowf A, Jennings D, Eberly S, Oakes D, Hawkins KA, Ascherio A, Stern MB, Marek K, PARS Investigators (2012) Impaired olfaction and other prodromal features in the Parkinson At-Risk Syndrome Study. Mov Disord 27, 406-412.

[12] Hoogendijk EO, Deeg DJH, de Breij S, Klokgieters SS, Kok AAL, Stringa N, Timmermans EJ, van Schoor NM, van Zutphen EM, van der Horst M, Poppelaars J, Malhoe P, Huisman M (2020) The Longitudinal Aging Study Amsterdam: Cohort update 2019 and additional data collections. Eur J Epidemiol 35, 61-74.

[13] Doty RL, Shaman P, Dann M (1984) Development of the University of Pennsylvania Smell Identification Test: A standardized microencapsulated test of olfactory function. Physiol Behav 32, 489-502.

[14] Folstein MF, Folstein SE, McHugh PR (1975) “Mini-mental state". A practical method for grading the cognitive state of patients for the clinician. J Psychiatr Res 12, 189-198.

[15] Creavin ST, Wisniewski S, Noel-Storr AH, Trevelyan CM, Hampton T, Rayment D, Thom VM, Nash KJ, Elhamoui H, Milligan R, Patel AS, Tsivos DV, Wing T, Phillips E, Kellman SM, Shackleton HL, Singleton GF, Neale BE, Watton ME, Cullum S (2016) Mini-Mental State Examination (MMSE) for the detection of dementia in clinically unevaluated people aged 65 and over in community and primary care populations. Cochrane Database Syst Rev, CD011145.

[16] Postuma RB, Arnulf I, Hogl B, Iranzo A, Miyamoto T, Dauvilliers Y, Oertel W, Ju YE, Puligheddu M, Jennum P, Pelletier A, Wolfson C, Leu-Semenescu S, Frauscher B, Miyamoto M, Cochen De Cock V, Unger MM, Stiasny-Kolster K, Fantini ML, Montplaisir JY (2012) A single-question screen for rapid eye movement sleep behavior disorder: A multicenter validation study. Mov Disord 27, 913-916.

[17] Radloff LS (1977) The CES-D Scale: A self-report depression scale for research in the general population. Appl Psychol Med 1, 385-401.

[18] Zigmond AS, Snaith RP (1983) The hospital anxiety and depression scale. Acta Psychiatr Scand 67, 361-370.

[19] Beekman AT, Deeg DJ, Van Limbeek J, Braam AW, De Vries MZ, Van Tilburg W (1997) Criterion validity of the Center for Epidemiologic Studies Depression scale (CES-D): Results from a community-based sample of older subjects in The Netherlands. Psychol Med 27, 231-235.

[20] Snaith RP (2003) The Hospital Anxiety and Depression Scale. Health Qual Life Outcomes 1, 29.

[21] Tanner CM, Gilley DW, Goetz CG (1990) A brief screening questionnaire for Parkinsonism. Ann Neurol 28, 267-268.

[22] Duarte J, Claveria LE, de Pedro-Cuesta J, Sempere AP, Coria F, Calne DB (1995) Screening Parkinson's disease: A validated questionnaire of high specificity and sensitivity. Mov Disord 10, 643-649.

[23] Longitudinal Aging Study Amsterdam, Functional limitations. https://lasa-vu.nl/topics/functional-limitations/,

[24] Attems J, Walker L, Jellinger KA (2015) Olfaction and aging: A mini-review. Gerontology 61, 485-490.

[25] Shprecher DR, Serrano GE, Zhang N, Intorcia A, Davis KJ, Glass M, Curry J, Walker J, Cutler B, Callan M, Garcia A, Sue LI, Beach TG (2020) Prevalence of REM sleep behavior disorder in Sun City, Arizona. Heliyon 6, e03140.

[26] Shprecher D, Zhang N, Halverson M, Savica R (2019) Parkinsonism risk factors in Salt Lake City, Utah: A community-based study. Brain Sci 9, 71.

[27] Yao C, Fereshtehnejad SM, Keezer MR, Wolfson C, Pelletier A, Postuma RB (2018) Risk factors for possible REM 
sleep behavior disorder: A CLSA population-based cohort study. Neurology 92, e475-e485.

[28] Pujol M, Pujol J, Alonso T, Fuentes A, Pallerola M, Freixenet J, Barbe F, Salamero M, Santamaria J, Iranzo A (2017) Idiopathic REM sleep behavior disorder in the elderly Spanish community: A primary care center study with a two-stage design using video-polysomnography. Sleep Med 40, 116-121.

[29] Chen H, Zhao EJ, Zhang W, Lu Y, Liu R, Huang X, Ciesielski-Jones AJ, Justice MA, Cousins DS, Peddada S (2015) Meta-analyses on prevalence of selected Parkinson's nonmotor symptoms before and after diagnosis. Transl Neurodegener $\mathbf{4}, 1$.

[30] Schrag A, Horsfall L, Walters K, Noyce A, Petersen I (2015) Prediagnostic presentations of Parkinson's disease in primary care: A case-control study. Lancet Neurol 14, 57-64.

[31] Abbott RD, Petrovitch H, White LR, Masaki KH, Tanner CM, Curb JD, Grandinetti A, Blanchette PL, Popper JS, Ross GW (2001) Frequency of bowel movements and the future risk of Parkinson's disease. Neurology 57, 456-462.

[32] Savica R, Carlin JM, Grossardt BR, Bower JH, Ahlskog JE, Maraganore DM, Bharucha AE, Rocca WA (2009) Medical records documentation of constipation preceding Parkinson disease: A case-control study. Neurology 73, 1752-1758.

[33] Langa KM, Levine DA (2014) The diagnosis and management of mild cognitive impairment: A clinical review. JAMA 312, 2551-2561.

[34] Lobo A, Launer LJ, Fratiglioni L, Andersen K, Di Carlo A, Breteler MM, Copeland JR, Dartigues JF, Jagger C, Martinez-Lage J, Soininen H, Hofman A (2000) Prevalence of dementia and major subtypes in Europe: A collaborative study of population-based cohorts. Neurologic Diseases in the Elderly Research Group. Neurology 54, S4-9.
[35] Darweesh SKL, Wolters FJ, Postuma RB, Stricker BH, Hofman A, Koudstaal PJ, Ikram MK, Ikram MA (2017) Association between poor cognitive functioning and risk of incident parkinsonism: The Rotterdam Study. JAMA Neurol 74, 1431-1438.

[36] Kok RM, Reynolds CF, 3rd (2017) Management of depression in older adults: A review. JAMA 317, 2114-2122.

[37] Fung AW, Chan WC, Wong CS, Chen EY, Ng RM, Lee EH, Chang WC, Hung SF, Cheung EF, Sham PC, Chiu HF, Lam M, Chiang TP, van Os J, Lau JT, Lewis G, Bebbington P, Lam LC, Hong Kong Mental Morbidity Survey Team (2017) Prevalence of anxiety disorders in community dwelling older adults in Hong Kong. Int Psychogeriatr 29, 259-267.

[38] Shiba M, Bower JH, Maraganore DM, McDonnell SK, Peterson BJ, Ahlskog JE, Schaid DJ, Rocca WA (2000) Anxiety disorders and depressive disorders preceding Parkinson's disease: A case-control study. Mov Disord 15, 669-677.

[39] Hattori M, Tsuboi T, Yokoi K, Tanaka Y, Sato M, Suzuki K, Arahata Y, Hori A, Kawashima M, Hirakawa A, Washimi Y, Watanabe H, Katsuno M (2020) Subjects at risk of Parkinson's disease in health checkup examinees: Cross-sectional analysis of baseline data of the NaT-PROBE study. J Neurol 267, 1516-1526.

[40] Pluijm SM, Bardage C, Nikula S, Blumstein T, Jylha M, Minicuci N, Zunzunegui MV, Pedersen NL, Deeg DJ (2005) A harmonized measure of activities of daily living was a reliable and valid instrument for comparing disability in older people across countries. J Clin Epidemiol 58, 10151023. 